(C) 2015. This manuscript version is made available under the CC-BY-NC-ND 4.0 license

http://creativecommons.org/licenses/by-nc-nd/4.0/

\title{
Becoming an expert: A masterclass in developing clinical expertise
}

\begin{abstract}
This Masterclass explores how practitioners may develop clinical expertise. The terms expert and expertise are initially outlined along with the attributes of a practitioner with expertise. This is followed by an exploration of the literature in relation to three key ways to develop expertise: through experience with patients, formal postgraduate education and through direct observation of practice with a mentor. The theoretical basis of these activities is critically reviewed to highlight their underpinning educational value and pedagogy. It is proposed that critical reflection on practice enhanced by direct observation of practice with a mentor and formal postgraduate education each provide a potentially powerful tool for learning and the development of clinical expertise.
\end{abstract}

Keywords

Clinical expertise, expert practice, osteopathy, osteopathic medicine, professional development, clinical reasoning 


\section{INTRODUCTION}

The aim of this Masterclass paper is to explore how osteopaths and health practitioners may develop their clinical expertise and perhaps become known by others as an expert. My knowledge in this area has come from over ten years experience as a course leader of a musculoskeletal physiotherapy postgraduate course that was primarily focused on developing expertise of practitioners, from doctoral research study exploring learning transitions of musculoskeletal physiotherapists undertaking the aforementioned course, and from supervision of research students from a range of healthcare professions exploring this topic area. This is not a definitive and comprehensive rendering of the subject, rather the perspective of the author as an educationalist and researcher and long ago practitioner, who has been exploring this topic for a number of years. It is hoped that this paper will help guide practitioners who wish to develop their clinical expertise and facilitate expertise in others.

\section{EXPERT AND CLINICAL EXPERTISE}

Dictionary definitions of an expert refer to someone who is very knowledgeable about, or skillful in, a particular area. ${ }^{1}$ This raises the issue of who decides the level of knowledge and skill needed and what criteria would determine whether someone is an expert. The complexity of osteopathic practice (and other health professionals) may not lend itself to a list of performance indicators on which to determine whether someone is 'an expert'. Perhaps the notion of someone being an expert is, like beauty, in the eye of the beholder; it is a concept constructed by the onlooker. The term 'expert' suggests a static and final position, however new knowledge is constantly being created, so how often would someone considered an expert need to be re-validated? Because of these difficulties in the term 'expert', the use of 'expertise' has generally been used in this paper, except where accuracy to the literature demands otherwise. Expertise has been referred to as the proficiency and judgment acquired through clinical experience and clinical practice. ${ }^{2}$ Expertise relates to a person's characteristics, skills and knowledge with a sense of it being fluid and changing. Clinical expertise is described here as the ability of the practitioner to effectively integrate their practice knowledge with the patient's clinical presentation, values and preferences to maximize the therapeutic encounter for the patient.

\section{ATTRIBUTES OF PRACTITIONERS WITH CLINICAL EXPERTISE}

In considering broadly the characteristics of expertise, the United Kingdom Quality Assurance Agency (QAA) for Higher Education learning outcomes for masters level learning (Table 1), provide a helpful overview. ${ }^{3}$ 
[Table 1 about here]

Narrowing down to the particular of clinical expertise, the literature provides a broad array of characteristics of a practitioner summarised in Table 2. The broad range of attributes include patient-centred practice, critical evaluation and understanding of their practice knowledge, and an ability to learn in and from their practice. A recent grounded theory study suggests that some of these characteristics may be found in experienced osteopaths. ${ }^{4,5}$

[Table 2 about here]

The last characteristic in Table 2, the capability to learn in, and from, practice (that is, to learn from experience) is considered essential to maintain expertise. ${ }^{8,10,35}$ To learn in, and from, practice requires practitioners to be capable of and disposed to critically examining, evaluating, creating, developing and transforming their practice knowledge and clinical practice. ${ }^{10,29,32,33,35}$ It is the questioning and challenging of practice knowledge that leads to its transformation. ${ }^{36}$ The practitioner therefore needs to be critically reflective and reflexive. ${ }^{32}$ The requirement to learn in, and from, practice embraces lifelong learning and highlights the importance of critical evaluation skills. ${ }^{27}$

\section{DEVELOPMENT OF CLINICAL EXPERTISE}

The developmental process by which practitioners enhance their clinical practice expertise is a contentious issue in the literature. Clinical practice experience with patients, formal postgraduate education and having mentors in practice were each considered instrumental in the professional development of clinical experts. ${ }^{8}$ These aspects provide a framework for this section and are discussed in turn.

\section{Clinical experience}

Expert level has been considered to develop from progressive accumulation of knowledge and skills through experience, however this is a controversial issue. ${ }^{6,37}$ Progressive accumulation of knowledge and skills assumes a conception of clinical practice as a mix of knowledge and skill divorced from clinical practice (technical rationality as described by Fish and Coles ${ }^{29}$, which seems inadequate. Despite this, two research studies have 
found that experienced practitioners (osteopaths and physiotherapists) viewed practice as the relatively simple application of knowledge and skills. ${ }^{38,39}$ Furthermore, the assumed progression of skill through the stages ${ }^{6}$ (novice, advanced beginner, competent, proficient and expert level) has not been identified amongst teachers, ${ }^{40,41}$ nurses, ${ }^{42}$ students, ${ }^{43,44}$ or engineers. ${ }^{30}$ According to Benner ${ }^{6(\mathrm{p} 32), 37}$, the expert nurse: has an intuitive grasp of each situation and zeroes in on the accurate region of the problem without wasteful consideration of a large range of unfruitful, alternative diagnoses and solutions... the expert operates from a deep understanding of the total situation...Highly skilled analytic ability is necessary for those situations with which the nurse has had no previous experience. Benner's notion of an expert nurse may also relate to an expert osteopath. However, while the description mirrors higher levels of motor skill performance ${ }^{45}$ and skilled behaviours under conditions of rapid decision making, ${ }^{10}$ it does not reflect the advanced cognitive abilities used in clinical practice ${ }^{10,45}$ to find solutions to indeterminate problems that require continuous experimentation. ${ }^{46}$ Furthermore in this model, expert practitioners are considered to be arational ${ }^{1}$, where intuition is considered to guide action. ${ }^{6,37}$ This is also difficult to accept since patient-centred care requires deliberative action. ${ }^{10,47}$

Within medicine, expert diagnostic reasoning has been theorised to develop through three stages: novice (knowledge that explains causal pathophysiological processes, for example causes of posterior leg pain), intermediate (encapsulation of biomedical knowledge into diagnostic labels, for example nerve root compression) and expert (illness script formation that emphasizes enabling conditions of a disease, for example lack of exercise). ${ }^{16,17,18}$ Clinical experience is considered vital to the development through each of these stages. ${ }^{16,17,18}$

The proposal that 10 years (or 10,000 hours) of deliberate practice develops expertise ${ }^{47,48}$ has been disputed. Deliberate practice accounted for one-third of the reliable variance in performance in chess and music with the proposal that age, intelligence and genetics may also be influential. ${ }^{49}$ Furthermore, a meta-analysis ${ }^{50}$ of 88 studies concluded that while the amount of deliberate practice was important in determining performance, it was not as influential as first thought. Deliberate practice accounted for $26 \%$ of the variance in performance in games, $21 \%$ for music, $18 \%$ for sports, $4 \%$ for education and less than $1 \%$ for professions. More specifically, musculoskeletal physiotherapy practitioners with better patient outcomes for people with low back pain, were

\footnotetext{
${ }^{1}$ Arational refers to being 'without conscious analytical decomposition and recombination' ${ }^{37}$ p36
} 
not distinguished by years of experience. ${ }^{51}$ Recent research in osteopathy also suggested that there is no

qualitative relationship between practitioner's level of clinical experience (years in clinical practice) and attributes of clinical expertise. ${ }^{4,5}$

The influence of experience on learning has been explored by Dewey ${ }^{52}$ who posited that every experience modifies the person and the quality of future experiences. So, for example, each experience an osteopath has of performing a spinal manipulation or carrying out a patient case history, will influence the practitioner and their subsequent experiences of manipulation and history taking. This notion is beginning to be borne out by studies exploring experience driven neuroplasticity highlighted in this journal by Esteves and Spence. ${ }^{53}$ This meaning making process may create or modify their practice knowledge (or personal theories), which may then modify them as practitioners, and influence their future clinical experience. ${ }^{29,54}$ The degree of change to their practice knowledge would thus depend on the degree to which they consciously reflected and theorised on the experience. The experience itself would, in turn, be influenced by the practitioner's hidden, taken for granted assumptions and expectations ${ }^{55,56,57}$ and this would be influenced by their clinical perspective or frame of reference, ${ }^{55,56}$ we tend to experience what we expect to experience. The potential for learning may therefore be limited as the practitioner may be trapped within their existing understanding, ${ }^{52,58}$ theories-in-use may be 'self-sealing ${ }^{2}{ }^{29}$ More radical transformation of practice knowledge may require help from other practitioners. They may reveal blind spots in practice knowledge ${ }^{60}$ and alternative views and paradigms that facilitate a more radical change..$^{55,56}$ This may lead to more complex and comprehensive understanding of practice knowledge with integration of knowing, acting and being, embodied and embedded in intersubjective practice. ${ }^{58,61}$

\section{reflection on experience}

The importance of reflection to experiential learning demands exploration. From the literature, a conceptual model of the relationship between experience and reflection is shown in Figure 1. The circular nature of experience suggests that experience that confirms expectations may not trigger as much reflection as a contradictory experience. A confirmatory clinical experience, accepted as such by the practitioner, may confirm and strengthen existing practice knowledge. A confirmatory clinical experience, rejected as such by the practitioner however, may trigger reflection and lead to modification of practice knowledge. The relationship between experience and reflection is illustrated by the following example. When presented with a person

\footnotetext{
${ }^{2}$ Self sealing refers to the situation where our theories limit what we do and therefore limit our opportunities to see something different.
} 
complaining of chronic low back pain, the practitioner may expect the person's pain and disability to respond to

hands-on manual therapy directed to the postural/structural and biomechanical clinical findings. If the person responds as expected this may confirm and reinforce the practitioner's beliefs and practice knowledge.

Alternatively, the practitioner may critically reflect on the experience and consider whether alternative treatment may have had a better and quicker response, this critical exploration may then lead to new insights and learning.

[Figure 1 about here]

In the same way, a contradictory clinical experience may be embraced, not noticed, ignored or rejected by a practitioner. ${ }^{63,64,65}$. A contradictory clinical experience that is ignored or rejected, may result in little change to practice knowledge; this may occur because of the risk of error, uncertainty or gap in practice knowledge, personal discomfort, ${ }^{59,66}$ or reluctance to make the intellectual effort required to reflect. ${ }^{10}$ Where a practitioner embraces a contradictory clinical experience, this may result in critical reflection towards their practice knowledge with subsequent modification. Using the same example as above, if the patient with low back pain does not respond as expected and fails to improve. The practitioner may chose to ignore this and continue to treat in the chosen way or make some minor modification to the treatment, with little learning. Alternatively, the practitioner may embrace this contradictory experience and critically reflect on their decision making process that may highlight missed cues, leading to an enhancement in their practice knowledge. In medical diagnostic reasoning, for example, a mismatch between patient information and the illness scripts and memory of previous patients held by expert practitioners is thought to trigger an active engagement in clinical reasoning. ${ }^{17,18}$

Thus confirmatory and contradictory clinical experience that is arrested and examined, ${ }^{67,68}$ develops, tests and generates practice knowledge. ${ }^{32}$ The capability to learn from experience depends not on years of experience, ${ }^{67,68,69}$ but rather on:

- $\quad$ the degree to which a practitioner reflects on clinical experience

- how questioning and critical a practitioner is of their clinical experience

- how open a practitioner is to changing their practice knowledge; and

- the degree to which a practitioner is exposed to alternative views and perspectives. 


\section{routinization with experience}

Experience not only creates and modifies practice knowledge, it also affects clinical behaviour and action. With repetition, actions can become more automatic, fluid and skillful. ${ }^{10,62}$ For example, palpation requires motor skills that can become automatic and highly skilled with practice. ${ }^{47}$ Automatic actions enhance time efficiency as well as the cognitive attention required to perform the action. For example, a habitual way to palpate the spine enables the practitioner to concentrate on feeling the paraspinal soft tissues and joint mobility. ${ }^{53}$ Automatic actions thus facilitate the application of practice knowledge (through cognition, metacognition and reflection) enabling conscious, deliberate patient-centred practice that enables the practitioner to learn from experience; this is highlighted in Table 3. Patient-centred practice is used here to denote the conscious, deliberate, creative, individualised and collaborative clinical care of patients. ${ }^{8,9,10,11,12}$ Practitioners developing in this way may have a conception of clinical practice as uncertain, unpredictable and problematic and a disposition to critically reflect and learn from their clinical practice, thus enhancing their practice knowledge with experience.

[Table 3 about here]

If, however, clinical actions are not accompanied by conscious use of practice knowledge (through cognition, metacognition and reflection), then there is a loss of conscious regulation and critical control, so that practice may become routinized; ${ }^{10,70}$ the process is summarised in Table 3 . There may be limited capability to learn from such practitioner-centred clinical practice (the routine use of examination procedures, treatment techniques and management strategies for patients regardless of their presentation). Practitioners developing in this way, may have a conception of clinical practice as certain, predictable and unproblematic and may not be disposed to critically reflect and learn from their clinical practice, thus limiting their practice knowledge.

\section{nature of clinical practice}

The nature of clinical practice may limit the opportunity to learn from experience. ${ }^{59,70}$ The practitioner:

- $\quad$ has to make clinical decisions for complex and uncertain problems; this may limit accurate and specific feedback on clinical decisions. ${ }^{10}$

- $\quad$ needs to be confident, committed and decisive with patients, but at the same time needs to be uncertain and critical towards their clinical practice and practice knowledge. ${ }^{10,59,70}$ Maintenance of this balance may be difficult. 
- may not value their own knowledge from clinical experience. ${ }^{71}$ The emphasis on evidence based practice and the use of propositional knowledge may devalue a practitioner's own knowledge gleaned from clinical experience.

\section{influence of work setting}

Work settings that value efficiency and patient through-put rather than effectiveness and quality of clinical practice ${ }^{10,63}$ may impede learning from experience in a number of ways identified in Table 4.

[Table 4 about here]

\section{$\underline{\text { Formal education }}$}

In the UK, university masters courses in musculoskeletal physiotherapy have a central aim to develop the clinical expertise of practitioners. These courses are approved by the Musculoskeletal Association of Chartered Physiotherapists (MACP) and must comply with the Educational Standards Document of the International Federation of Orthopaedic Manipulative Physical Therapists (IFOMPT). ${ }^{74}$ These courses have a minimum of 200 hours of theory, 150 hours of practical skill development and 150 hours of mentored clinical practice. Research has demonstrated that practitioners completing these courses gained enhanced confidence, clinical reasoning, criticality, ability to engage with evidence based practice, ability to learn and career development and were more patient-centred..$^{73,75,76}$ Some of these elements were found within a theoretical model of the learning transition (change in attitude, knowledge and behavior) of musculoskeletal physiotherapists completing a MACP approved MSc, ${ }^{38,77}$ this is shown in Figure 2. This research study showed that at the start of the course, participants typically held uncritical practice knowledge and tended towards routine, practitioner-centred clinical practice. The learning transition varied between participants and depended on a host of moderating factors. At the end of the course, participants enhanced their practice in terms of three inter-related aspects: they gained a critical understanding of practice knowledge that facilitated more patient-centred practice, which led to a capability to learn in and from practice (Figure 3). This development towards clinical expertise was primarily facilitated by critical evaluation of practice knowledge, and was particularly powerful when facilitated by a mentor in clinical practice; this involved the direct observation of practice with patients with subsequent questioning, discussion and critical feedback. This highly challenging experience necessitated high levels of support from the mentor. From the perspective of osteopathy, a recent grounded theory study resonates with the 
above theory. Osteopaths with formal postgraduate education demonstrated a range of attributes associated with

clinical expertise, such as adopting a more critical and reflective stance towards practice knowledge, norms and traditions; adopting a person-centred approach towards patient management; and were comfortable with the ambiguity and uncertain terrain of professional clinical practice. ${ }^{4,5}$ These rewards may offset the financial costs for osteopaths working in private practice.

[Figure 2 and Figure 3 about here]

\section{Mentors in practice}

The notion of a mentor facilitating the development of a practitioner's clinical expertise is consistent with the literature related to situated learning; in this context, learning in and from practice. ${ }^{910,29,32,58,69,88}$ Someone with expertise guiding a less experienced practitioner is well rehearsed in the literature ${ }^{9,89,90}$ and the role of the mentor is summarised in Table 5. It is argued here, that mentorship that involves direct observation with patients may be a powerful method of enhancing clinical expertise. The value of direct observation of practice, highlighted in Table 6, may be due to every aspect of practice being observed, which is then followed by immediate and specific feedback of performance and discussion. Even practitioners of similar levels of knowledge may benefit from observing each other in clinical practice.

[Table 5 and 6 about here]

Critical dialogue of practice knowledge creates opportunities for individuals to experience contradiction that may trigger learning. ${ }^{58,59,63,64,95,99,100}$ Unlike confirming experience which may lead to minimal learning, contradictory experiences can lead to a powerful learning transition with significant cognitive and emotional dissonance. ${ }^{99}$ Critical dialogue of practice knowledge with the mentor exposes practitioners to alternative views and perspectives that can free them from their own circular experience and understanding. ${ }^{52,58,59}$ The less experienced are guided to a higher level of practice knowledge and understanding through cognitive scaffolding and structuring. ${ }^{101}$ This process may lead to a transformation of practice knowledge that is more discriminating, integrated, differentiated, open, dependable and justified. ${ }^{55,92}$ This highlights the need for the mentor to challenge, question and offer new knowledge that contradicts the mentees current knowledge. The mentee, in turn, needs to be prepared to face contradictory knowledge and consider alternative points of view. 
Opportunity for the practitioner to observe the practice of those with higher levels of expertise may also be of benefit; observational learning has been highlighted as a powerful process ${ }^{9,10,82}$ The observer may gain confidence seeing similar actions to their own as well as seeing alternative ways of working. The observed may act as a role model demonstrating a higher level of practice that identifies areas for further development in the observing practitioner.

Direct observation of practice may initially be resisted by practitioners as they may feel vulnerable to negative judgment of their practice and a loss of respect from their colleagues. While lone working in a clinic room with patients may protect the practitioner from any criticism, it prevents them from being encouraged and supported and misses the opportunity to share and learn from colleagues; and thus make it difficult to develop a high level of clinical expertise. Mentorship with direct observation of practice will, however, be challenging. For practitioners in sole practice settings, geographical distance may limit access. To successfully implement mentorship, it would be imperative to use a mentee-centred approach and that a collaborative, respectful relationship is developed between mentee and mentor. If this can be achieved, mentorship would appear to offer a potentially powerful and economical method of enhancing the clinical expertise of practitioners. While the American Osteopathic Association has a well established mentor exchange programme (http://cf.osteopathic.org/iLearn/home.cfm), the recent initiative to develop and pilot a supportive mentoring programme for UK osteopathy graduates ${ }^{102}$ may prove fruitful.

\section{CONCLUSION}

Just as 'the more you know, the more you know you don't know' is a truism, so the notion of an expert is 'a chasing after the wind'. ${ }^{103}$ The best that can be hoped for is a developing expertise that will continue as a lifelong process. Once accepted that learning is a necessary and continuous process for practitioners, the next question of importance is how best to learn and develop. The literature suggests that passively gaining years of experience will not automatically lead to the development of expertise and expert practice. A practitioner has to actively and critically engage with their practice, seeking out and embracing contradictory experiences and challenging confirmatory experiences in order to use these as vehicles to learn and enhance their practice knowledge. Critical reflection on practice is fundamental to this. In addition, direct observation of practice and mentorship provide 
practitioners with a potentially powerful process in which to share knowledge and gain alternative and broader 1 ways of working that can lead to high levels of clinical expertise. 


\section{REFERENCES}

1. Oxford Dictionary Accessed 9.8.14 http://www.oxforddictionaries.com/definition/english/expert.

2. Sackett DL. Evidence-based medicine. Seminars in Perinatology 1997;21:30.

3. Quality Assurance Agency for Higher Education (2008) Framework for higher education qualifications in England, Wales and Northern Ireland. Retrieved 5.8.14 from:

http://www.qaa.ac.uk/en/Publications/Documents/Framework-Higher-Education-Qualifications-08.pdf.

4. Thomson OP, Petty NJ, Moore AP. Clinical decision-making and therapeutic approaches in osteopathy a qualitative grounded theory study. Man Ther 2014;19:44-51.

5. Thomson OP, Petty NJ, Moore AP. A qualitative grounded theory study of the conceptions of clinical practice in osteopathy- a continuum from technical rationality to professional artistry Man Ther 2014; 19: 37-43.

6. Benner P. From novice to expert, excellence and power in clinical nursing practice. California: AddisonWelsey; 1984.

7. Jensen GM, Gwyer J, Shepard KF, Hack LM. Expert practice in physical therapy, Phys Ther 2000; 80: 28-43.

8. Martin C, Siosteen A, Shepard KF. The professional development of expert physical therapists in four areas of clinical practice, In: Jensen GM, Gwyer J, Hack LM, Shepard KF, editors. Expertise in physical therapy practice. Boston: Butterworth Heinemann; 1999.

9. Titchen A. Critical companionship: a conceptual framework for developing expertise. In: Higgs J, Titchen A, editors. Practice knowledge and expertise in the health professions. Oxford: Butterworth Heinemann; 2001. P. 80-90.

10. Eraut M. Developing professional knowledge and competence. London: RoutledgeFalmer; 1994.

11. Higgs J, Titchen A. Knowledge and reasoning. In: Higgs J, Jones M, editors. Clinical reasoning in the health professions, 2nd ed. Oxford: Butterworth Heinemann; 2000. P. 23-32.

12. Johns C. Becoming a reflective practitioner, 2nd ed. Oxford: Blackwell; 1998.

13. Benner P. Using the Dreyfus model of skill acquisition to describe and interpret skill acquisition and clinical judgement in nursing practice and education. Bull Sci Technol and Soc 2004; 24: 188-99.

14. Glaser R. Expert knowledge and processes of thinking. In: McCormick R, Paechter C, editors. Learning and knowledge. London: Paul Chapman; 1999. P. 88-102.

15. Milidonis MK, Godges JJ, Jensen GM. Nature of clinical practice for specialists in orthopaedic physical therapy. J Orthop Sports Phys Ther 1999; 29: 240-47.

16. Schmidt HG, Norman GR Boshuizen HPA A cognitive perspective on medical expertise: theory and implications. Acad Med 1990; 65: 611-621

17. Schmidt HG, Rikers RMJP How expertise develops in medicine: knowledge encapsulation and illness script formation. Med Educ 2007; 41:1133-1139.

18. Boshuizen HPA, Schmidt HG The development of clinical reasoning expertise. In: In: Higgs J, Jones MA, Loftus S, Christensen N, editors. Clinical reasoning in the health professions, 3rd ed. Amsterdam: Elsevier; 2008. P113-121.

19. Benner P, Tanner CA, Chesla CA. Expertise in nursing practice: caring, clinical judgment, and ethics. New York: Springer; 1996.

20. Higgs J, Jones M. Clinical reasoning in the health professions, 2nd ed. Oxford: Butterworth-Heinemann; 2000 . 
21. McEwen IR. Paediatric expert practice, In: Jensen GM, Gwyer J, Hack LM, Shepard KF, editors. Expertise in physical therapy. Boston: Butterworth Heinemann; 1999 P. 247-52.

22. Jensen GM, Gwyer J, Hack LM, Shepard KF. Expertise in physical therapy practice. Boston: Butterworth Heinemann; 1999.

23. Sternberg RJ, Horvath JA. A prototype view of expert teaching. Educ Res 1995; 24: 9-17.

24. Eraut M. Non-formal and tacit knowledge in professional work. Br J Educ Psychol 2000; 70:113-36.

25. Kinchin IM, Cabot LB, Hay DB. Using concept mapping to locate the tacit dimension of clinical expertise: towards a theoretical framework to support critical reflection on teaching. Learn Health Soc Care 2008;7:93-104.

26. Boshuizen HPA. Medical education: or the art of keeping a balance between science and pragmatics. In: McCormick R, Paechter C, editors. Learning and knowledge. London: Paul Chapman; 1999; P. 185-97.

27. Caney D. Competence - can it be assessed? Physiotherapy 1983;69: 302-4.

28. Eisner EW. The art of educational evaluation, a personal view. London: Falmer; 1985.

29. Fish D, Coles C. Developing professional judgement in health care. Oxford: Butterworth-Heinemann; 1998.

30. Sandberg J. Understanding human competence at work: an interpretative approach. Acad Manage J 2000;43:9-25.

31. Tynjala P. Towards expert knowledge? A comparison between a constructivist and a traditional learning environment in the university. Int J Educ Res 1999;31:357-442.

32. Rolfe G. Beyond expertise: reflective and reflexive nursing practice. In: Transforming nursing through reflective practice. Johns C, Freshwater D editors. Oxford: Blackwell Science; 1998 P. 21-31.

33. Billett S. Knowing in practice: re-conceptualising vocational expertise. Learn Instr 2001;11:431-52.

34. Daley BJ. Novice to expert: an exploration of how professional learn. Adult Educ 1999; 49:133-47.

35. Kennedy MM. Inexact sciences: professional education and the development of expertise. Rev of Res Educ 1987;14:133-67.

36. Cranton P. Understanding and promoting transformative learning, 2nd ed. San Francisco: Jossey-Bass; 2006.

37. Dreyfus HL, Dreyfus SE. Mind over machine: the power of human intuition and expertise in the era of the computer. New York: Free; 1986.

38. Petty NJ, Scholes J, Ellis L. The impact of a musculoskeletal masters course: developing clinical expertise. Man Ther 2011;16:590-5.

39. Thomson OP, Petty NJ, Moore AP. A qualitative grounded theory study of the conceptions of clinical practice in osteopathy - a continuum from technical rationality to professional artistry. Man Ther 2014; 19:37-43.

40. Huberman M. Professional careers and professional development: some intersections. In: Guskey TR, Huberman M editors. Professional development in education, new paradigms and practices. Teachers College, Columbia University; 1995. P.193-224.

41. Mevarech ZR. Teachers' paths on the way to and from the professional development forum. In: Guskey TR, Huberman M editors. Professional development in education, new paradigms and practices. Teachers College, Columbia University; 1995. P.151-70. 
42. Rischel V, Larsen K, Jackson K. Embodied dispositions or experience? Identifying new patterns of professional competence. J Adv Nurs 2008;61:512-21.

43. Beaty E, Morgan A. Developing skill in learning. J Open Distance Learn 1992;7:3-11.

44. Marton F, Dall'Alba G, Beaty E. Conceptions of learning. Int J Educ Res 1993;19:277-300.

45. Johns C, Freshwater D. Transforming nursing through reflective practice. Oxford: Blackwell; 1998.

46. Engestrom Y, Engestrom R, Karkkainen M. Polycontextuality and boundary crossing in expert cognition: learning and problem solving in complex work activities. Learn Instr 1995;5:319-36.

47. Ericsson KA. The influence of experience and deliberate practice on the development of superior expert performance. In: Ericsson KA, Charness N, Feltovich PJ, Hoffman RR, editors. The Cambridge handbook of expertise and expert performance. Cambridge: Cambridge University. 2006; P. 683-703.

48. Ericsson KA, Krampe R Th, Tesch-Romer C. The role of deliberate practice in the acquisition of expert performance. Psycholog Rev 1993;100:363-406.

49. Hambrick DZ, Oswald FL, Altmann EM, Meinz EJ, Gobet F, Campitelli G. Deliberate practice: is that all it takes to become an expert? Intell 2014;45:34-45.

50. Macnamara BN, Hambrick DZ, Oswald FL Deliberate practice and performance in music, games, sports, education, and professions: a meta-analysis. Psychological Sci 2014; 25: 1608-1618

51. Resnik L, Jensen GM. Using clinical outcomes to explore the theory of expert practice in physical therapy. Phys Ther 2003; 83:1090-106.

52. Dewey J. Experience and education. New York: Touchstone; 1938/1997.

53. Esteves JE, Spence C. Developing competence in diagnostic palpation: perspectives from neuroscience and education. Int J Osteopath Med 2013;17:52-60.

54. Eraut M. Editorial, The many meanings of theory and practice. Learn Health Soc Care 2003; 2:61-5.

55. Mezirow J. Transformative dimensions of adult learning. California: Jossey-Bass; 1991.

56. Mezirow J. Learning as transformation, critical perspectives on a theory in progress. San Francisco: JosseyBass; 2000.

57. Schutz A. The phenomenology of the social world. London: Heinemann Educational Books; 1972.

58. Dall'Alba G, Sandberg J. Unveiling professional development: a critical review of stage models. Rev Educ Res 2006;76:383-412.

59. Argyris C, Schon DA. Theory in practice, increasing professional effectiveness. San Francisco: Jossey-Bass; 1974.

60. Luft J. Of human interaction. California: National Books; 1969.

61. Dall'Alba G. Understanding professional practice: investigations before and after an educational programme. Studies High Educ 2004;29:679-92.

62. Jarvis P. The practitioner-researcher. Developing theory from practice. San Francisco: Jossey-Bass; 1999.

63. Eraut M. Knowledge creation and knowledge use in professional contexts. Studies in High Educ 1985;10:117-33.

64. Schon DA. The reflective practitioner, how professionals think in action. Aldershot: Ashgate Arena; 1991. 
65. Titchen A, Ersser SJ. Explicating, creating and validating professional craft knowledge. In: Higgs J, Titchen A, editors. Practice knowledge and expertise in the health professions. Oxford: Butterworth Heinemann; 2001. P. 48-56.

66. Gamble J, Chan P, Davey H. Reflection as a tool for developing professional practice knowledge and expertise. In: Higgs J, Titchen A, editors. Practice knowledge and expertise in the health professions. Oxford: Butterworth Heinemann; 2001. P.121-7.

67. Boud D, Cohen R, Walker D. Using experience for learning. Buckingham: The Society for Research into Higher Education \& Open University; 1993.

68. Criticos C. Experiential learning and social transformation for a post-apartheid learning future. In: Boud D, Cohen R, Walker D, editors. Using experience for learning. Buckingham: The Society for Research into Higher Education \& Open University; 1993. P.157-68.

69. Usher RS, Bryant I. Re-examining the theory-practice relationship in continuing professional education. Studies High Educ 1987;12:201-12.

70. Eraut M. Editorial Continuity of learning. Learn Health Soc Care 2005;4:1-6.

71. Usher RS. Beyond the anecdotal: adult learning and the use of experience. Stud Educ Adults 1985;17:59-74.

72. Blaikie N. Approaches to social enquiry. Cambridge: Polity; 1993.

73. Stathopoulos I, Harrison K. Study at Master's level by practising physiotherapists. Physiotherapy 2003;89:158-69.

74. Rushton A, Petty N. The course approval board of the manipulation association of chartered physiotherapists. Man Ther 2002;7:222-8.

75. Green A, Perry J, Harrison K. The influence of a postgraduate clinical master's qualification in manual therapy on the careers of physiotherapists in the United Kingdom. Man Ther 2007;13:139-47.

76. Rushton A, Lindsay G. Defining the construct of masters level clinical practice in manipulative physiotherapy. Man Ther 2010; 15(1): 93-9.

77. Petty NJ, Scholes J, Ellis L. Masters level study: learning transitions towards clinical expertise in physiotherapy Physiotherapy 2011;97:218-25.

78. Belenky MF, Clinchy BM, Goldberger NR, Tarule JM. Women's ways of knowing, 10th ed. New York: Basicbooks; 1986.

79. $\mathrm{Ng} \mathrm{KC}$, Murphy D, Jenkins W. The teacher's role in supporting a learner-centred learning environment: voices from a group of part-time postgraduate students in Hong Kong. Int J Lifelo Learn 2002;21:462-73.

80. Dweck CS. Self-theories: their role in motivation, personality and development. Philadelphia: Psychology Press; 2000.

81. Weiner B. Achievement motivation and attribution theory. Morristown: General Learning; 1974.

82. Bandura A. Self perceived self efficacy, the exercise of control. New York: WH Freeman and Co; 1997.

83. Fennell M. Overcoming low self-esteem, a self help guide using cognitive behavioural techniques. London: Constable and Robinson; 1999.

84. Hopson B. Transition: understanding and managing personal change. In Griffiths D (ed) Psychology and medicine. London: British Psychological Society and Macmillan; 1981. P. 323-48.

85. Goleman D. Emotional intelligence. London: Bloomsbury; 1996. 
86. Harris TA. I'm ok-you're ok. London: Pan Books; 1973.

87. Kolb DA. Experiential learning. Englewood Cliffs: Prentice-Hall; 1984.

88. Billett S. Workplace participatory practices. Conceptualising workplaces as learning environments. J Workpl Learn 2004;16:312-24.

89. Fish D, Twinn S. Quality clinical supervision in the health care professions. Principled approaches to practice. Edinburgh: Butterworth-Heinemann; 1997.

90. Daloz LA. Mentor, guiding the journey of adult learners. San Francisco: Jossey-Bass; 1999.

91. Graffam B. Deriving better questions: creating better clinical instruction. Clin Teach 2008;5: 98-102.

92. Cranton P. Individual differences and transformative learning. In Mezirow J (ed) Learning as transformation, critical perspectives on a theory in progress. California: Jossey-Bass; 2000. P.181-204.

93. Eraut M. Editorial, learning to change and/or changing to learn. Learn Health Soc Care 2004; 3:111-17.

94. Griffiths D. Stress. In: Griffiths D, editor. Psychology and medicine. London: British Psychological Society and Macmillan; 1981. P. 296-322.

95. Scholes J. An exploration of role transition in students converting from enrolled nurse (general) to registered general nurse. Sussex University: Unpublished DPhil; 1995.

96. Fish D. Appreciating practice in the caring professions. Oxford: Butterworth-Heinemann; 1998.

97. Jones MA. Orthopedic expert practice. In: Jensen G M, Gwyer J, Hack L M, Shepard K F, editors. Expertise in physical therapy practice. Boston: Butterworth Heinemann; 1999. P. 264-70.

98. Titchen A, Ersser SJ. The nature of professional craft knowledge. In: Higgs J, Titchen A editors. Practice knowledge and expertise in the health professions. Oxford: Butterworth Heinemann; 2001. P. 35-41.

99. Scholes J. Developing expertise in critical care nursing. Oxford: Blackwell; 2006.

100. Titchen A, Ersser SJ. Explicating, creating and validating professional craft knowledge. In: Higgs J, Titchen A, editors. Practice knowledge and expertise in the health professions. Oxford: Butterworth Heinemann; 2001. P. 48-56.

101. Tharp RG, Gallimore R. Rousing minds to life: teaching, learning, and schooling in social context. Cambridge: Cambridge University; 1988.

102. Institute of Osteopathy. 2014 Retrieved 29.12.14 from http://jobs.timeshighereducation.co.uk/Upload/attachments/THES/117264/Invitation\%20to\%20Tender\%20Ment oring\%2009\%2006\%202014.pdf)

103. Holy Bible. New International Version. Ecclesiastes. 1991;4:4. Colorado Springs: International Bible Society. 
Thanks to Dr Ollie Thomson for reviewing this manuscript and providing very helpful and insightful comments and additions. 


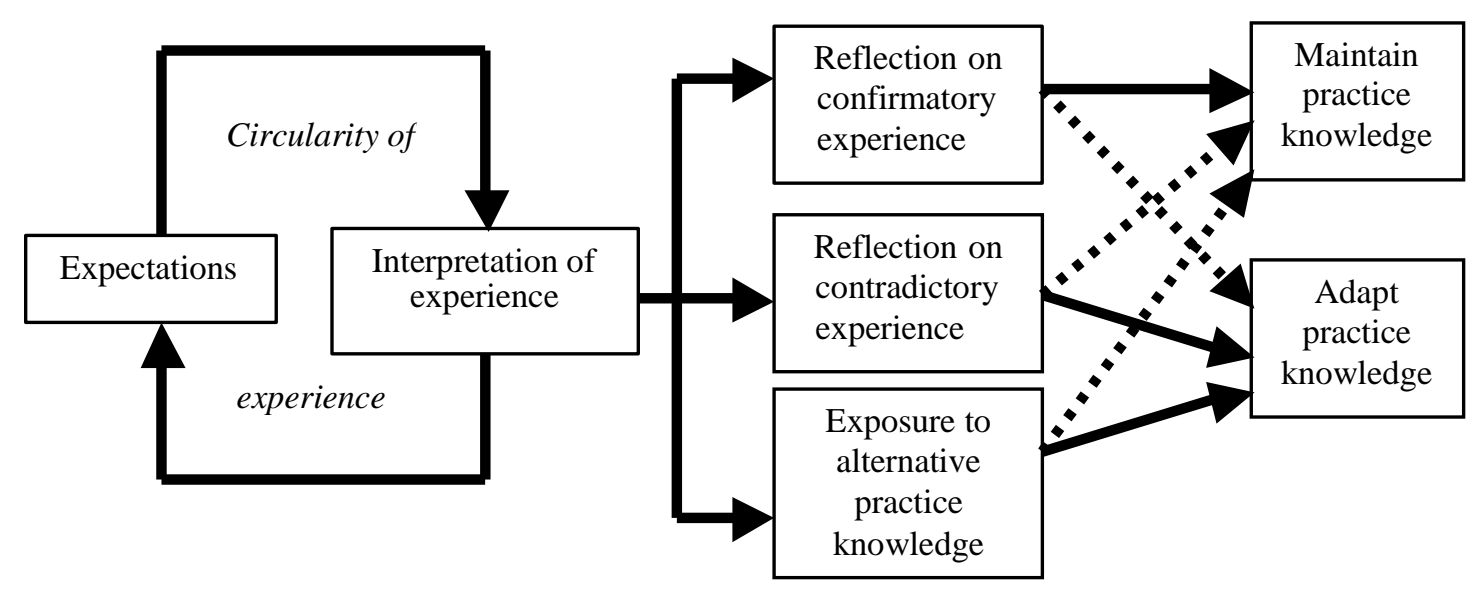

Figure 1

Circular nature of experience and reflection on learning. (Adapted from Dewey ${ }^{52}$, Eraut ${ }^{54}$, Fish and Coles ${ }^{29}$ Jarvis $^{62}$ ).

$\ldots \boldsymbol{D}=$ rejection

$=$ acceptance 


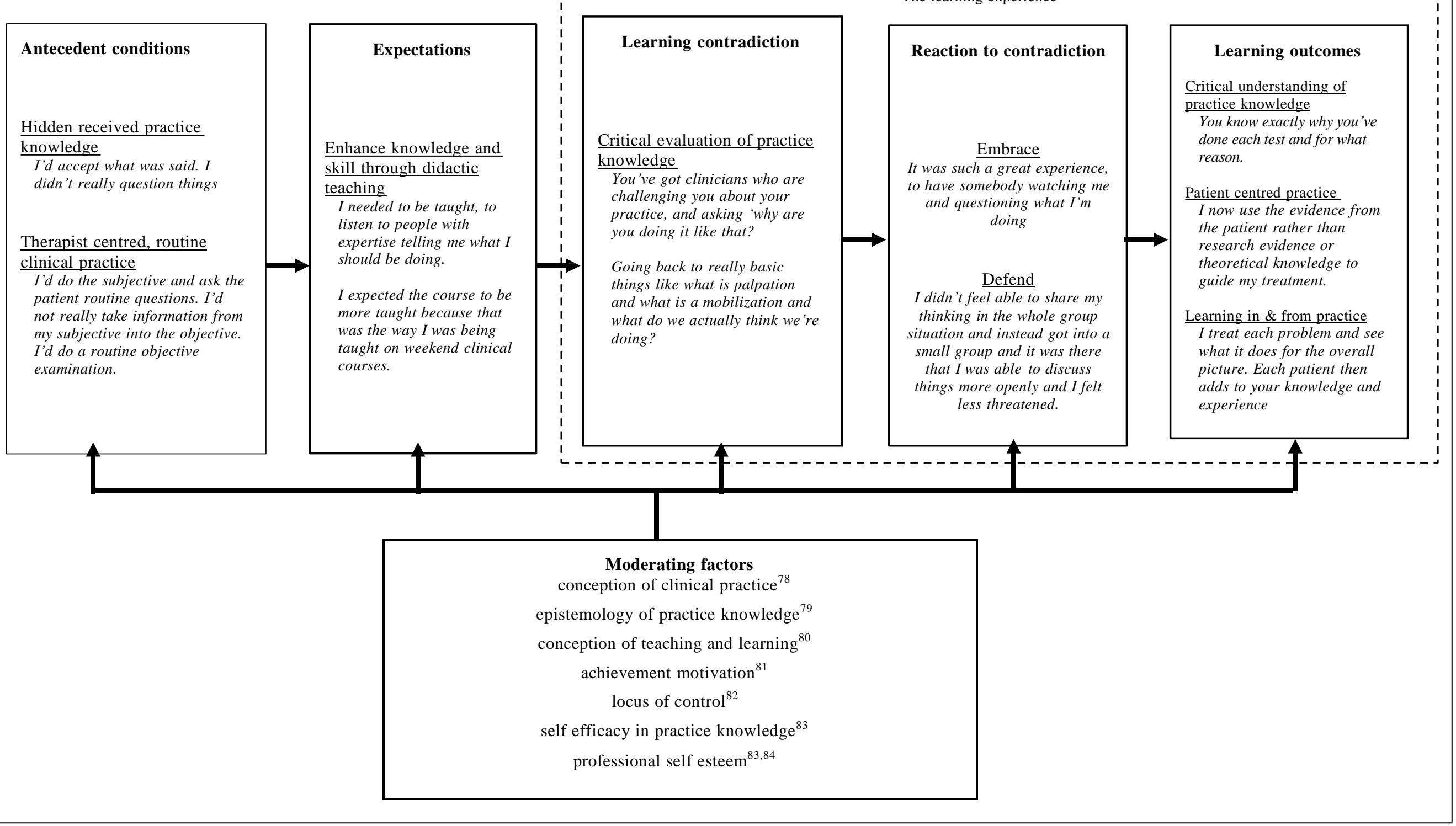

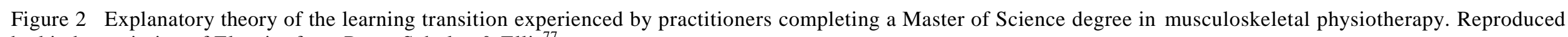
by kind permission of Elsevier from Petty, Scholes \& Ellis 


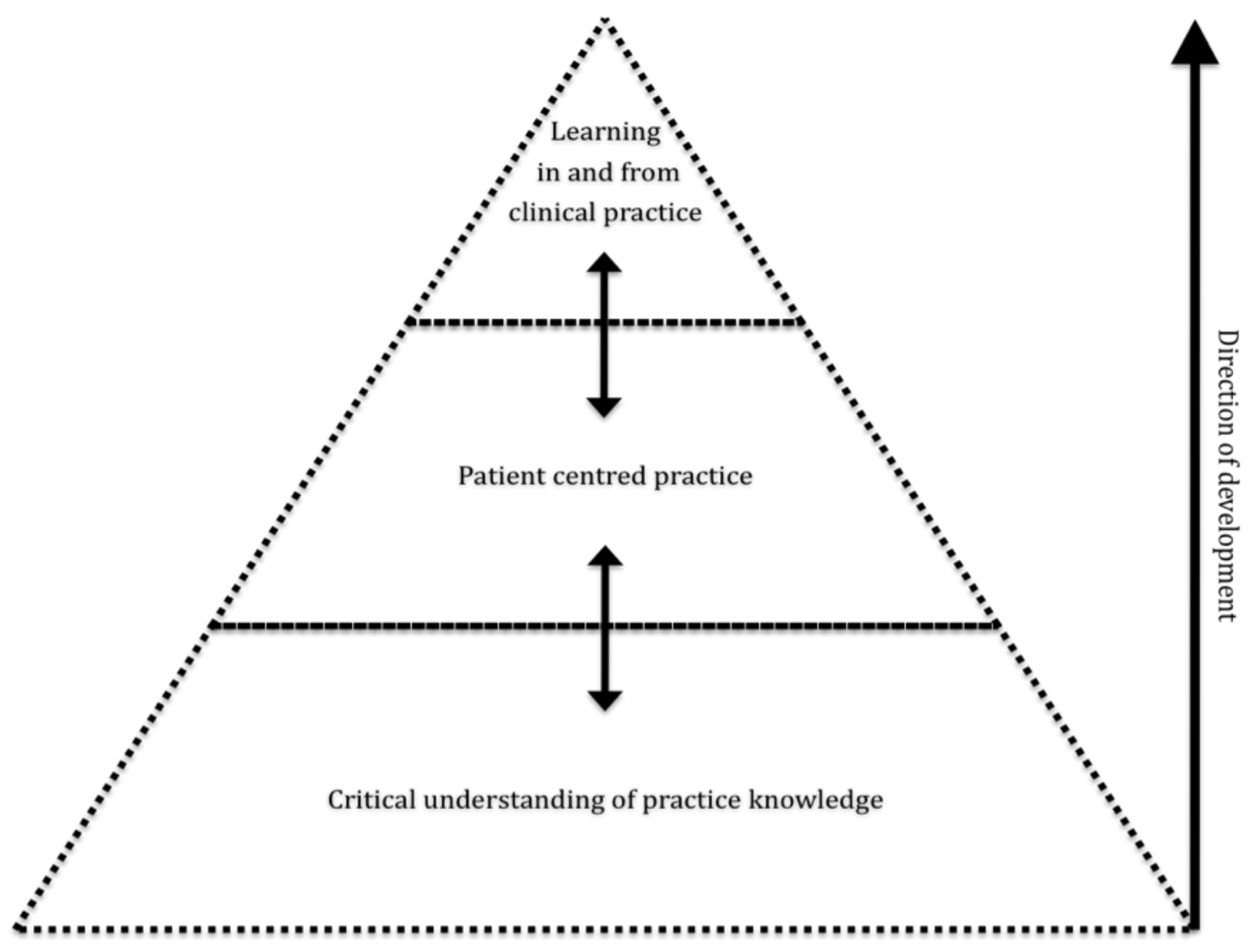

Figure 3

The learning outcome of the Master of Science degree in musculoskeletal physiotherapy. The direction of development towards clinical expertise involved three developmental aspects: critical understanding of practice knowledge led to patient centred practice, which in turn led to a capability to learn in, and from, clinical practice. The smaller arrowheads indicate that learning in and from practice enhanced patient centred practice, which in turn enhanced critical understanding of practice knowledge. Reproduced by kind permission of Elsevier from Petty, Scholes \& Ellis. ${ }^{77}$ 
Typically holders will be able to:

- deal with complex issues systematically and creatively, make sound judgments in the absence of complete data, and communicate their conclusions clearly to specialist and non-specialist audiences

- demonstrate self-direction and originality in tackling and solving problems, and act autonomously in planning and implementing tasks at a professional level

- continue to advance their knowledge and understanding, and to develop new skills to a high level

And holders will have:

- the qualities and transferable skills necessary for employment requiring:

- the exercise of initiative and personal responsibility

- decision-making in complex and unpredictable situations

- the independent learning ability required for continuing professional development

Table 1 Documented learning outcomes of Masters level 7 learning. ${ }^{3}$ 


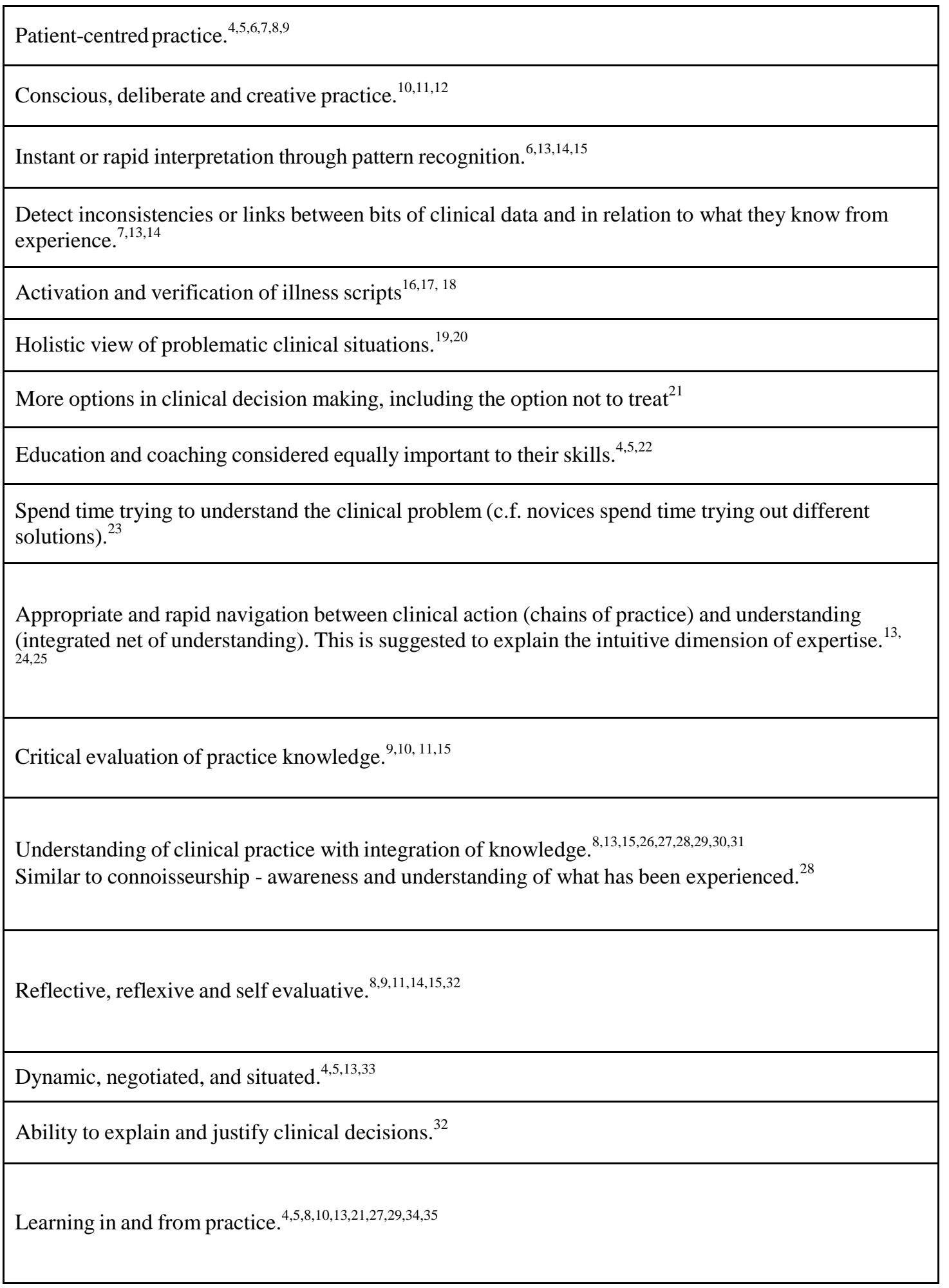

Table 2 Attributes of a practitioner with clinical expertise 


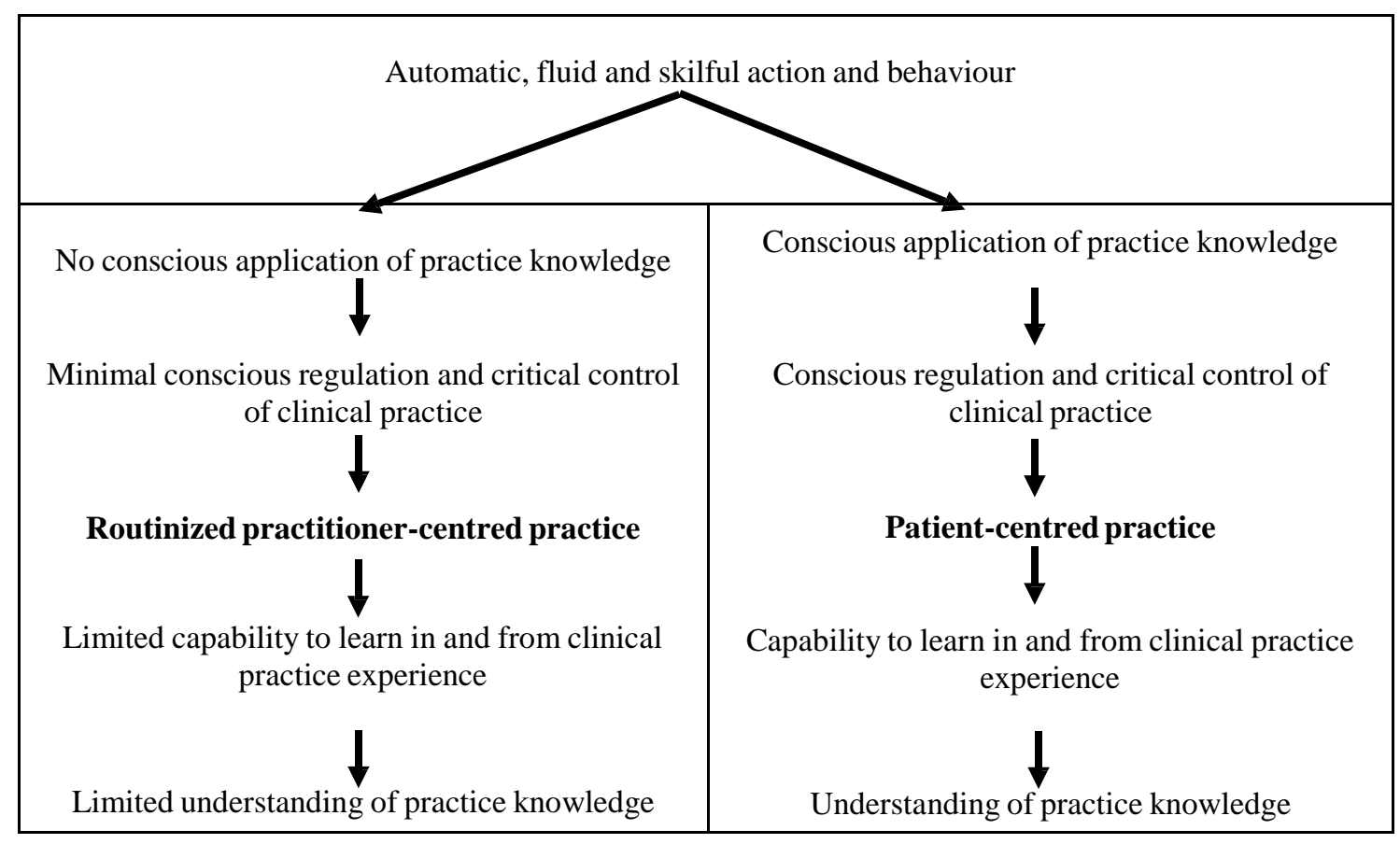

Table 3 The nature of practitioner-centred and patient-centred clinical practice. (Adapted from Eraut ${ }^{10,70}$ and Jarvis $^{62}$ ) 
Practice setting may inhibit practitioners learning by:

- $\quad$ promoting the use of routines and habits in practice

- $\quad$ limiting time for cognitive and metacognitive processing

- $\quad$ promoting superficial reflection on actions and solutions through single loop learning rather than deep reflection that might question the premises on which action was taken through double loop learning. ${ }^{59}$

- $\quad$ engendering the use of pattern recognition* and a trial and error approach at the expense of reflective deliberation and an abductive reasoning $* *$ approach to patient management. ${ }^{32,72}$

- $\quad$ limiting time and opportunity to critically reflect on clinical experience

- $\quad$ inhibiting any change to practice as the process of change often requires time

- $\quad$ promoting lone working with patients and prevent practitioners working together and learning from each other. $^{10,73}$

- $\quad$ promoting therapist centred practice

Table 4 Ways in which the practice setting can inhibit learning from experience.

* It is not suggested here that the use of pattern recognition is a sign of therapist centred practice; rather that time constraints in an efficiency driven workplace may hinder an abductive approach where this may be needed.

** Abductive reasoning involves the generation of new ideas and hypotheses to help explain phenomena in the data, in this context, the patient's presentation. ${ }^{72}$ 
The mentor provides:

- high level challenge toward uncritically assimilated taken-for-granted assumptions, beliefs, values, expectations, perceptions, judgments, actions and perspectives. ${ }^{9}$

- $\quad$ questions the learner's practice knowledge. ${ }^{33}$ Questioning can trigger reflection and reveal understanding, as well as promote collaborative construction of knowledge. ${ }^{91}$

- critical dialogue to promote collaborative interpretations and critique, and evaluation to promote deliberation and reflection. ${ }^{9}$

- practice knowledge broken down into its constituent parts. Each part is then made more complex and more distinguishable by being refined, differentiated and elaborated through critical evaluation. ${ }^{87}$

- guidance for cognitive organisation to remain at the level of principles for flexible and creative clinical practice and to facilitate integrative development of understanding with further experience. ${ }^{87}$

- opportunity for knowledge to become more discriminating, integrated, differentiated, open, ${ }^{55}$ dependable and justified. ${ }^{92}$

- $\quad$ high levels of support ${ }^{9}$ to counterbalance the learning transition that may involve less fluid and more difficult practice, disorientation, vulnerability, and even alienation with strong feelings of anxiety, stress, and irritability. ${ }^{10,93,95}$

Table 5 The role of the mentor 


\begin{tabular}{|l|l|}
\hline Nature of practice knowledge & Direct observation of clinical practice \\
\hline $\begin{array}{l}\text { Embedded within action and rarely discussed, } \\
\text { debated or critically appreciated. }{ }^{29}\end{array}$ & $\begin{array}{l}\text { Can trigger articulation and critical evaluation of } \\
\text { knowledge embedded within action. }{ }^{59}\end{array}$ \\
\hline $\begin{array}{l}\text { Hidden like an iceberg from practitioners so they } \\
\text { are unaware of what informs their clinical } \\
\text { actions. }{ }^{29,59,96}\end{array}$ & $\begin{array}{l}\text { Awareness raised through comprehensive, direct } \\
\text { and specific feedback of performance by } \\
\text { another. }{ }^{10,22,89,97}\end{array}$ \\
\hline $\begin{array}{l}\text { Tacit or difficult to articulate } \\
\text { palpation findings }\end{array}$ & $\begin{array}{l}\text { Enables aspects that cannot be articulated to be } \\
\text { shared in other ways, for example comparing } \\
\text { palpation findings. }\end{array}$ \\
\hline $\begin{array}{l}\text { Outside the control of the practitioner }{ }^{10} \text { and as } \\
\text { such cannot be changed. }{ }^{59}\end{array}$ & $\begin{array}{l}\text { Comes under the control of the practitioner }{ }^{10} \text { and } \\
\text { so can be changed. }{ }^{59}\end{array}$ \\
\hline
\end{tabular}

Table 6 Value of direct observation of clinical practice 